Peckham, National Children's Bureau, 8 Wakley Street, Islington, London ECIV 7QE.

\section{References}

1 Gardiner, P A, Factors Associated with the Development of Myopia in the Growing Child. New York, Myopia Research Foundation, 1964.

${ }^{2}$ Karlsson, J L, Clinical Genetics, 1975, 8, 314.

3 Davie, R, Butler, N, and Goldstein, H, From Birth to Seven. London, Longman and the National Children's Bureau, 1972.

4 Putler, N R, and Alberman, E, (editors), Perinatal Problems. Edinburgh, Livingstone, 1969.

5 Start, K B, and Wells, B K, The Frequency Reading Standards. Slough, National Foundation for Educational Research, 1972.

${ }^{6}$ Fogelman, K, and Goldstein, H, Educational Studies (Oxford), 1976, 2, No 2, 95 .
'Peckham, C S, and Adams, B, Child Care, Health, and Development, $1975,1,93$.

${ }^{8}$ Douglas, J W B, Ross, J M, and Simpson, H R, fournal of the Royal Statistical Society, 1967, 130, 479.

${ }^{9}$ Registrar-General's Classification of Occupations. London, HMSO, 1960.

10 Gardiner, P A, Lancet, 1954, 1, 476.

11 Ministry of Education, Health of the School Child, Report of the Chief Medical Officer for the Years 1952 and 1953, Ch 9, p 78. London, HMSO, 1954.

12 Ministry of Health, A Historical Sketch of the Origins, Development and Present Organisation of the School Health Service, Report of the Chief Medical Officer of Health and Principal Schools Medical Officer for 1954, p 24. London, HMSO, 1955.

13 Sorsby, A, Sheridan, M, and Leary, G A, Refraction and its Components in Twins. London, HMSO, 1962.

(Accepted 22 December 1976)

\title{
Patients in acute surgical wards: a survey in Glasgow
}

\author{
I W STRANG，F A BODDY，BRYAN JENNETT
}

British Medical fournal, 1977, 1, 545-548

\section{Summary}

A survey was made of all patients in general surgical, urological, and orthopaedic and accident wards in Glasgow on one day in June 1975. Its purpose was to define features of acute surgical practice of relevance to the future planning of resources, particularly bed numbers. Over $40 \%$ of the patients in both surgical and orthopaedic wards were over 65 years. Most patients had serious conditions and could not have been treated other than by admission to an acute surgical ward. But a substantial minority no longer needed such facilities and could have been transferred to second-line beds, although many still required skilled nursing care. Delay in the discharge of elderly patients from acute surgical wards as a consequence of non-surgical (often medical or social) problems results in a proportion of acute surgical beds fulfilling a second-line function. Unless arrangements for the earlier discharge of these patients are made any reduction in acute surgical beds is likely to restrict elective surgery, especially in orthopaedics.

\section{Introduction}

"Norms" for the provision of acute hospital beds are now being used in planning the future provision of surgical services.

\footnotetext{
Greater Glasgow Health Board

I W STRANG, MB, DIPSOCMED, senior registrar in community medicine BRYAN JENNETT, MD, FRCS, chairman of area subcommittee on surgery,* and professor of neurosurgery, University of Glasgow

Department of Community Medicine, University of Glasgow

F A BODDY, MRCP, FFCM, senior lecturer in operational studies in health care

${ }^{*}$ Members of the area subcommittee on surgery were: Professor $\mathrm{L} \mathrm{H}$ Blumgart, Professor D L Hamblen, Mr K Fraser, Mr J S F Hutchison, Mr C W Imrie, Mr A Litton, Mr A Marshall, Mr D C Miln, Mr E A Osborne, Mr Gavin Smellie, Mr D C Smith, Mr J White, Mr G A Whitefield, Mr I C Whyte.
}

Relating a declared norm to estimates of the future local population produces a simple statement of limits within which surgical services must be constrained. The assumption that both the present pattern of surgical morbidity and present techniques of surgical practice will continue unchanged may, however, be challenged. A more serious objection is that planning procedures of this kind assume that acute beds are in fact used for acute cases. There is little allowance for the inappropriate use of these facilities that may arise because services of other kinds are inadequate in some areas.

In October 1975 the Greater Glasgow Health Board circulated a discussion document ${ }^{1}$ that proposed an overall reduction of acute beds by 1991 . The projected bed numbers were based on an expected fall in population and the application of a desired rate of "patient throughput" proposed by the Scottish Home and Health Department (throughput is the average number of patients per bed per year). This method of estimation resulted in the proposal to reduce the number of acute surgical and urological beds from about 1200 to 690 and orthopaedic and accident beds from 720 to 360 -that is, an overall reduction of $45 \%$. When the area subcommittee in surgery was invited to comment it considered that there was need for objective data about certain aspects of the use of surgical beds and the characteristics of surgical patients. The Orthopaedic Council in Glasgow had already begun a limited inquiry of this kind, and the community medicine specialists whom the Council had consulted were invited to broaden their inquiry. The collaborative survey which followed is described here.

\section{Objectives}

The survey was planned to describe the pattern of surgical work and to define those features of surgical inpatient care that may be relevant to the planning of future resources. We were particularly interested in the problem of discharging elderly patients once their surgical treatment had been completed and in the possible use of "second-line" beds as an alternative way of caring for patients who no longer needed acute facilities.

\section{Methods}

The survey took the form of a census of all inpatients in general surgical, urological, and accident and orthopaedic beds in the area of the Greater Glasgow Health Board at 9.00 am on 19 June 1975. 
One hazard of census surveys of this kind is that the day chosen for the survey may not be typical. Inquiries made of each surgeon concerned and comparisons with other routine statistical data suggested, however, that there was no reason to consider that this day was unusual. The data may thus be regarded as a reasonable cross-section of the day-to-day pattern of surgical work in Glasgow.

Two sources of data were used in the survey. A questionnaire about each patient was completed by the consultant surgeon or his immediate deputy. The form recorded age and sex, the diagnosis and any surgical procedure that had been undertaken or planned and inquired about the presence or absence of several factors relevant to the management or the discharge and aftercare of the patient and the patient's need on that day or in the immediate future for a number of specific services (such as operating theatre facilities or special nursing procedures). Further questions concerned expectations for the patient's discharge, his suitability for a second-line bed, and his most appropriate destination on discharge. The surgeon was also asked to choose one of a series of statements describing, in general terms, the patient's surgical and nursing needs. The second document was a version of the nursing dependency form developed by Barr and his colleagues at Oxford. ${ }^{2}$ This is a well-tested form and it was completed for each ward in the survey by the ward sister with data for each patient.

In addition to the usual pilot procedures for testing the feasibility of the protocols, all aspects of the survey were discussed with the surgeons who were to complete the documents. This process of consultation, together with the fact that the survey was initiated by surgeons themselves, probably accounted for the high degree of co-operation we experienced. Only one surgical unit did not participate, and there were valid reasons for this. As a check on the completeness of the survey we obtained the numbers of occupied beds from Health Board sources for the night before the survey. By these counts 1607 beds were occupied, and 1663 survey forms were completed-an "excess" of patients of $3.5 \%$. This was explained by the different times of day at which the two counts were made.

\section{Results}

The results refer to Glasgow as a whole. Both general surgical and urological patients were grouped together as "surgical" patients and orthopaedic and accident patients as "orthopaedic" ones. Although there were differences between the five districts in the health board's area, the similarities between patient characteristics in the various districts were more striking.

Age and sex-The significant feature of the age and sex distribution of the patients (table $\mathrm{A}^{*}$ ) was the proportion of patients who were aged 65 or over $-42 \%$ of the surgical patients and $44 \%$ of the orthopaedic patients. Patients over the age of 74 constituted $37 \%$ of the women on orthopaedic wards.

Length of stay-The number of days the patient had been in hospital was related to age and was strikingly greater over the age of 64 , with very long lengths of stay being particularly associated with older patients. Ninety per cent of surgical patients under the age of 65 had spent less than 28 days in hospital, while the corresponding period for patients over 74 was 55 days (table I). Orthopaedic patients generally stayed longer: $90 \%$ of those aged under 65 had been in hospital for under 79 days compared with a 90th percentile of 136 days for patients aged over 74

Older patients in both the surgical and the orthopaedic groups were rather more likely to have been admitted as emergency cases: $43^{\circ} \%$ surgical patients and $49^{\circ}{ }_{\circ}$ of orthopaedic patients aged over 74 years *Copies of tables A-E may be obtained from the authors. were admitted as emergencies compared with $29 \%$ and $41 \%$ respectively of those aged under 65

Causes of admission to surgical wards-The diagnostic categories of the patients (table B) presented a rather different picture from that provided by analyses based on such larger-scale aggregate data as Hospital Activity Analysis or the Scottish Hospital Inpatient Statistics. Annual data tend to overemphasise the shorter-stay conditions, such as inguinal hernia, and reduce the significance of more complex diagnoses when the content of the surgical work load at a given point in time is being considered. The census provided a more realistic cross-sectional view of the day-to-day pattern of surgical work but tended to understate the importance of simpler conditions in the overall work of surgical units.

With this proviso in mind, there are several aspects of the diagnostic data that relate to our observations on the number of days the patients had been in hospital. Malignancies were the cause of admission for about one in eight men and one in five women; $7 \%$ of all first diagnoses were malignancies of the digestive system. A similar proportion $(9 \%)$ of patients were in hospital for diseases of arteries (predominantly peripheral vascular disease), and $4 \%$ had diseases of veins. Non-malignant diseases of the digestive system were the cause of admission in just over a third of the men and in just under half the women. Within this broad group, all hernias (including hiatus hernia) comprised $4 \%$ of diagnoses. Inguinal hernia was the first diagnosis for only 21 patients or $1.3 \%$ of the total. From the standpoint of the nature and provision of surgical services, these observations illustrate the preponderance of "serious" disease in the day-to-day make-up of the population of patients in surgical beds. It would be difficult to argue that there had not been sound reasons for the admission of most of the patients in this survey to an acute surgical unit. Alternative forms of management - such as outpatient or day-hospital surgerywould have been appropriate for only a small proportion of the patients who were in hospital on the day of the census.

Causes of admission to orthopaedic wards-Two-thirds of the men and half women were admitted as a result of accidents, and fractures of the lower limbs comprised $35 \%$ of all orthopaedic diagnoses. Almost half $(45 \%)$ of the men with fractures of the lower limb were aged under 45 years. By contrast, $75 \%$ of the women with lower limb fractures were aged 65 or over, and two-thirds $(63 \%)$ were over 74 years old. A third of the orthopaedic patients had diseases of the musculoskeletal system, of which rheumatoid arthritis $\left(7^{\circ} \%\right.$ of cases) and osteoarthritis $(11 \%)$ were the most common. The proportion of patients with fractures of the neck of the femur $(17 \%)$ almost exactly equalled the proportion in hospital with arthritic conditions. As with the surgical wards, it would be difficult to argue that there had not been good cause for the admission of most patients. In view of the proportion of patients admitted as emergency cases, any attempt to reduce the number of beds without improving arrangements for discharging patients can only reduce the number of admissions for elective procedures.

\section{SURGICAL AND NURSING NEEDS OF PATIENTS}

The stage of treatment of the patients was assessed by the surgeon, who allocated each patient to the most appropriate of six general descriptive categories (table $\mathrm{C}$ ). About two-thirds of the patients were in the three most therapeutically active categories, but it seems that $20-30^{\circ}$ of the patients in both acute surgical and orthopaedic wards might have been adequately cared for in less elaborate or expensive facilities. This must, of course, be a tentative conclusion: some of these patients would have been close to discharge and, for the remainder, both the character of second-line beds and their relation to the parent acute unit merit further exploration.

TABLE I-Time in hospital and type of admission

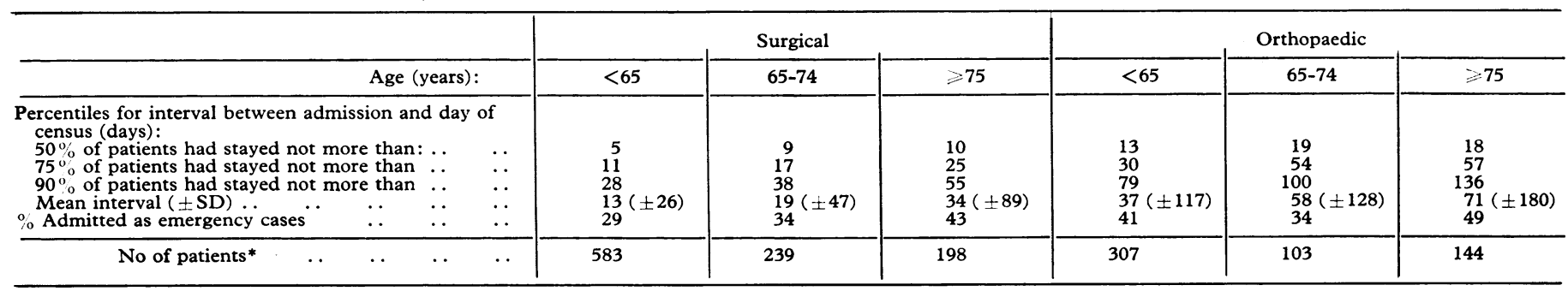


To define the needs of these patients more precisely, we asked the surgeons which of a list of specific services each patient was likely to require on the day of the survey as part of the treatment planned for him. (The list included the need for operating theatre facilities, $x$-ray investigations or other special procedures, complex drug administration, etc). Roughly two-thirds of the surgical patients required, or were likely to require, at least one of the facilities usually associated with acute units (table $\mathrm{D}$ ). About a quarter of the patients did not need these services but did require the supervision of a wound and the oversight of a resident doctor. About one in 10 of the surgical patients who had been in hospital for less than 10 days and almost one in five of those who had been inpatients for 10 days or more needed none of the listed services.

The pattern of need for specific services among the orthopaedic patients was essentially the same. A relevant point of difference between the surgical and orthopaedic patients was that $42 \%$ of the surgical patients who had been in hospital for 10 or more days needed no more complex service than the supervision of a wound or a resident doctor, or both, whereas this proportion for the similar group of orthopaedic patients was $29^{\circ} \mathrm{n}$. The difference was in the need for $x$-ray facilities: the proportion of orthopaedic patients rose to $49 \%$ when this service was added to the grouping.

\section{PROBLEMS OF MANAGEMENT AND AFTERCARE}

Several factors relevant to the current management of the patients, or likely to be relevant in considering arrangements for discharge or aftercare, were analysed in relation to the age of the patients (table II). Problems of management among patients aged under 65 years were uncommon in both surgical and orthopaedic groups, although problems of locomotor disability were obviously common among the orthopaedic patients. In patients aged over 64 , however, the frequency of management problems of various kinds rose sharply: $40 \%$ of the male surgical and $47 \%$ of the female surgical patients were described as having "physical weakness," and $34 \%$ of the male surgical patients had their management complicated by cardiorespiratory disability. In the view of the surgeons $15 \%$ of all patients over 65 years had psychiatric problems that influenced their care. In this older age group locomotor disability was not only a problem of orthopaedic patients; it was also a relevant factor for $20 \%$ of the surgical patients.

Problems of discharge or aftercare were similarly uncommon among younger patients whether in surgical or orthopaedic units. The two principal factors in the over-64 age group were, as expected, unsatisfactory home circumstances $(15 \%$ of all patients over 64$)$ and the lack of caring relatives $(22 \%$ of all patients over 65$)$.

There was a clear relation between problems of this kind and length of stay in hospital (table E). Physical weakness was a problem for $44 \%$ of the surgical patients who had been in hospital for over 30 days compared with $21 \%$ of those with a shorter stay in hospital. Similarly, psychiatric problems were reported for $19 \%$ of the long-stay patients compared with only $8 \%$ of the remainder. Twenty-eight per cent of the long-stay surgical patients had adverse home circumstances (compared with $5 \%$ of the others), and one-third lacked a suitable caring relative. Again, the same pattern emerged for orthopaedic patients who had been in hospital for more than 45 days: $20 \%$ of these patients were said to have a psychiatric problem, a quarter lacked appropriate home circumstances, and a similar proportion had no caring relative.

\section{NURSING DEPENDENCY}

A further important element was the nursing need of the patients. The data in table III were derived from the Oxford Nursing Dependency Study protocol, but the degrees of dependency shown in part A

TABLE II-Problems in present management or aftercare of patients. Results are percentage of patients with each problem in each age and sex group

\begin{tabular}{|c|c|c|c|c|c|c|c|c|c|c|c|}
\hline & & & & \multicolumn{4}{|c|}{ Surgical } & \multicolumn{4}{|c|}{ Orthopaedic } \\
\hline & & & & \multicolumn{2}{|c|}{ Men } & \multicolumn{2}{|c|}{ Women } & \multicolumn{2}{|c|}{ Men } & \multicolumn{2}{|c|}{ Women } \\
\hline & & \multicolumn{2}{|r|}{ Age (years): } & $<65$ & $\geqslant 65$ & $<65$ & $\geqslant 65$ & $<65$ & 65 & $<65$ & $\geqslant 65$ \\
\hline \multicolumn{12}{|c|}{ Current management } \\
\hline $\begin{array}{l}\text { Physical weakness } \quad \ldots \\
\text { Psychiatric problems } \quad \ldots \\
\text { Locomotor disability } \\
\text { Cardiorespiratory disability } \\
\text { Gastrointestinal disability } \\
\text { Genitourinary disability.. }\end{array}$ & $\begin{array}{l}\cdots \\
\cdots \\
\cdots \\
\cdots\end{array}$ & $\begin{array}{l}\cdots \\
\cdots \\
\cdots \\
\cdots\end{array}$ & $\begin{array}{ll}. & \cdots \\
\cdots & \cdots \\
\cdots & \cdots \\
\cdots & \cdots \\
\cdots & \cdots\end{array}$ & $\begin{array}{r}14 \\
7 \\
9 \\
12 \\
9 \\
11\end{array}$ & $\begin{array}{l}40 \\
14 \\
21 \\
34 \\
11 \\
33\end{array}$ & $\begin{array}{r}14 \\
5 \\
9 \\
8 \\
13 \\
7\end{array}$ & $\begin{array}{l}47 \\
14 \\
22 \\
17 \\
18 \\
12\end{array}$ & $\begin{array}{r}8 \\
4 \\
40 \\
4 \\
1 \\
1\end{array}$ & $\begin{array}{r}36 \\
13 \\
41 \\
16 \\
2 \\
5\end{array}$ & $\begin{array}{r}6 \\
5 \\
33 \\
5 \\
1 \\
3\end{array}$ & $\begin{array}{r}38 \\
18 \\
38 \\
8 \\
2 \\
10\end{array}$ \\
\hline \multicolumn{12}{|c|}{ Discharge or aftercare } \\
\hline $\begin{array}{l}\text { Complex treatment } \\
\text { Unsatisfactory home circumsta } \\
\text { Lack of caring relatives ... } \\
\text { Lack of community services } \\
\text { Home remote from Glasgow }\end{array}$ & $\begin{array}{l}\ldots \\
\text { ances } \\
\cdots \\
\cdots \\
\cdots\end{array}$ & $\begin{array}{l}\cdots \\
\because \\
\cdots \\
\cdots\end{array}$ & $\begin{array}{l}\ldots \\
\cdots \\
\cdots \\
\cdots\end{array}$ & $\begin{array}{l}4 \\
6 \\
7 \\
2 \\
4 \\
\end{array}$ & $\begin{array}{r}5 \\
12 \\
15 \\
3 \\
4\end{array}$ & $\begin{array}{l}6 \\
3 \\
4 \\
3\end{array}$ & $\begin{array}{r}8 \\
15 \\
27 \\
5 \\
4\end{array}$ & $\begin{array}{l}2 \\
4 \\
5 \\
8\end{array}$ & $\begin{array}{r}6 \\
17 \\
32 \\
6 \\
11\end{array}$ & $\begin{array}{r}4 \\
10 \\
9 \\
1 \\
4\end{array}$ & $\begin{array}{r}3 \\
16 \\
20 \\
6 \\
6\end{array}$ \\
\hline No of patients* .. & $\ldots$ & $\ldots$ & $\ldots$ & 313 & 204 & 270 & 233 & 169 & 54 & 138 & 190 \\
\hline
\end{tabular}

*These details were not known for six surgical patients and seven orthopaedic patients.

TABLE III-Nursing characteristics of patients. Results are percentages of patients in each age and sex group

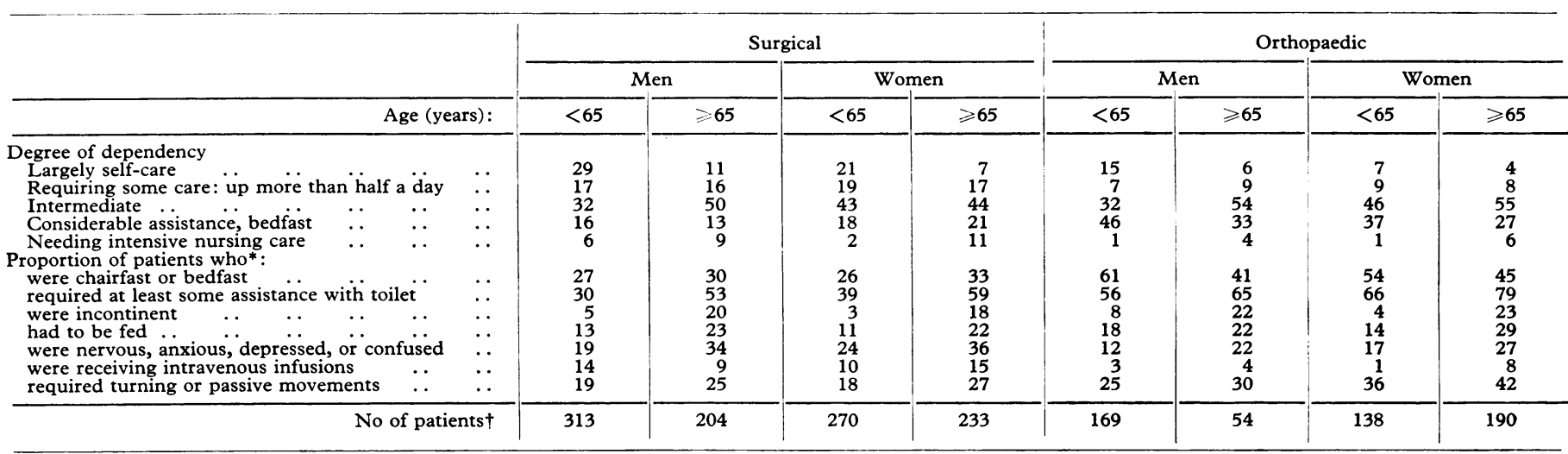

*The percentages in this part of the table refer to the proportion of patients in each group with that characteristic; for this reason they do not add to $100 \%$.

The percentages in this part of the table refer to the proportion of patients in each group
tThese details were not known for six surgical patients and seven orthopaedic patients. 
of the table were not strictly comparable with those used by the operational research unit at Oxford. ${ }^{2}$ The nursing data generally confirmed the picture provided by the surgeons. They showed that on the day of the survey most patients (about two-thirds) required the level of nursing care that is found in acute surgical or orthopaedic units. Naturally the older patients were more dependent, and this was more pronounced in the orthopaedic than the general surgical wards: $91 \%$ of men and $88 \%$ of women aged more than 65 in orthopaedic wards compared with $72 \%$ of men and $76 \%$ of women over 65 in surgical wards were in the upper three categories of dependency. Recalling the significance of older women in orthopaedic practice $\left(58^{\circ}{ }_{\circ}\right.$ were over 65$)$, it is relevant that $45 \%$ of female orthopaedic patients over 65 were chairfast or bedfast; $79^{\circ}$ required help with toilet; $27 \%$ were nervous, anxious, depressed or confused; and $42 \%$ required turning or passive movements. These patients comprised $35^{\circ}$ of all the orthopaedic patients in the survey. Similarly, female surgical patients over the age of 64 made up $23 \%$ of all surgical patients: $59 \%$ required help with toilet; $18 \%$ were incontinent; $36 \%$ were nervous, anxious, depressed, or confused; $22 \%$ had to be fed; and $27^{\circ} \%$ required turning or passive movements.

\section{Discussion}

Several factors with which our survey was not concerned are also relevant to the provision of acute surgical beds. These include estimates of the future size and age and sex characteristics of the population to be served and the extent of the unmet need for services, which may be reflected in the size of waiting lists. On the other hand, surveys of this kind can draw attention to existing circumstances and help planning by showing the character of the needs that are likely to exist in the future. It is apparent, for example, that some of the acute beds in Glasgow are fulfilling a second-line function, so that estimates of the "proper" number of acute beds for the future should take account of this present blurring definition. This argument may be carried further and attention drawn to the interrelation between emergency and elective admissions. For example, a combination of the inescapable emergency admissions of elderly women with fractures of the neck of the femur and difficulties in their later discharge from acute beds may reduce the availability of elective orthopaedic procedures for younger patients. Although the total population served by the Greater Glasgow Health Board is expected to fall in the next 15 years, this reduction in size will not be uniform in all age and sex groups. In particular, people aged over 64 in 1991 are expected to form $16 \%$ of the predicted population, in contrast to $13 \%$ at present. $^{3}$

When we related these estimates to the proportions of patients occupying surgical or orthopaedic beds at a particular time we were struck by the prominence of conditions such as fractured neck of the femur, peripheral vascular disease, and the "major" cancers such as those of the large bowel. It may therefore be more sensible to view the overall provision of surgical facilities in terms of an "aggregate" of services for a fairly wide range of particular causes and patients' needs. Thus, rather than use a blanket projection of bed requirements, it would be desirable to try to estimate the future provision that would be necessaryfor example, for peripheral vascular surgery, the acute management of cancer, less complex procedures such as inguinal hernia, and so on. Data for these estimates already exist in the Hospital Activity Analysis and the Scottish Hospital Inpatient Statistics.

Such estimates would primarily relate to the need for admission to acute surgical beds. The second major point to emerge from the survey is the need to consider closely the character and function of second-line beds and, more generally, the relation between surgical, orthopaedic, and geriatric services. If "a bed" and the resources associated with it fulfil different functions at different stages in a patient's hospital stay it is possible to define the need for second-line beds for a fairly substantial proportion of surgical or orthopaedic patients. But it is also necessary to consider carefully the different functions that such beds will have to fulfill for different groups of patients. Some patients will need to convalesce and be rehabilitated, while others will need more explicitly surgicalgeriatric services, which permit a closer collaboration between the two specialties. Developments along these lines should be more properly regarded as a reorientation of existing resources on the basis of the requirements of patient care rather than as "economies" or reductions in bed numbers. To take one instance, it is doubtful whether significant economies in nursing provision could be made in providing second-line care for many of the longer-stay patients. There are also practical difficulties, not least in resolving such problems as the physical relation between acute and second-line beds and the difficulty of achieving an appropriate balance of numbers in the context of a single hospital or even a single district.

The data presented in this paper are a greatly condensed version of a more detailed account of characteristics of surgical and orthopaedic services in Glasgow. The value of the detailed analysis was, perhaps, that it enabled both surgeons and planners to develop a clearer picture of the nature of surgical services and the needs of the patients they care for. In this sense we hope that studies of this kind, which, we feel, are worth repeating or developing in other contexts, will be seen as a necessary part of the clinician's involvement in National Health Service management and as part of the wider problem of adapting existing services to the changing needs of patients.

We are grateful to our surgical and orthopaedic colleagues for their active interest and collaboration in this joint project. Professor D L Hamblen contributed helpful comments and criticism at several stages of its progress. Mrs Frances Sinclair was responsible for the administrative and secretarial aspects of the survey, and Mrs M M Wyllie and Mrs M H Potter provided expert help with the coding of the data. The Greater Glasgow Health Board provided financial support.

Copies of the unpublished tables may be obtained from Dr F A Boddy, Department of Community Medicine, University of Glasgow, Ruchill Hospital, Glasgow G20 9NB.

\section{References}

${ }^{1}$ Greater Glasgow Health Board, Acute Bed Survey. Mimeograph, 1975. 2 Operational Research Unit, Nursing Dependency in the Medical Wards. Oxford, Oxford Regional Hospital Board, 1971.

3 Annual Report of the Registrar-General for Scotland, 1974, part 2, Population and Vital Statistics. Edinburgh, HMSO, 1976.

(Accepted 24 December 1976) 